\title{
Hyperosmolar nonketotic coma precipitated by lithium-induced nephrogenic diabetes insipidus
}

\author{
H Azam, RW Newton, AD Morris, CJ Thompson
}

\begin{abstract}
Summary
A 45-year-old man, with a 10-year history of manic depression treated with lithium, was admitted with hyperosmolar, nonketotic coma. He gave a five-year history of polyuria and polydipsia, during which time urinalysis had been negative for glucose. After recovery from hyperglycaemia, he remained polyuric despite normal blood glucose concentrations; water deprivation testing indicated nephrogenic diabetes insipidus, likely to be lithiuminduced. We hypothesize that when this man developed type 2 diabetes, chronic polyuria due to nephrogenic diabetes insipidus was sufficient to precipitate hyperosmolar dehydration.
\end{abstract}

Keywords: hyperosmolar coma; lithium; diabetes insipidus

Hyperosmolar nonketotic coma (HONK) typically occurs in older patients with noninsulindependent diabetes mellitus and has a mortality rate of up to $60 \% .^{1}$ There are many recognised precipitating factors including infection, cardiovascular disease, and drugs, particularly corticosteroids and thiazide diuretics. ${ }^{2}$ We report a case of HONK which occurred when diabetes mellitus developed in the setting of chronic polyuria associated with lithiuminduced diabetes insipidus.

\section{Case report}

A 45-year-old Caucasian man presented to the emergency room having collapsed at home. $\mathrm{He}$ had a two-week history of severe polyuria, nocturia and polydipsia. He had been treated with lithium for manic depressive psychosis for 10 years and for five years prior to admission he had experienced mild polyuria and nocturia which was not of sufficient severity to prompt him to seek medical attention; on several occasions during this time, however, routine urinalysis performed by his general practitioner had failed to show glycosuria. He had no other medical history and his only medication was lithium. There was no family history of diabetes mellitus or insipidus. He admitted to drinking 10 units of alcohol per week, but had not taken alcohol for one week prior to admission.

On examination, he was drowsy, but conscious and clinically dehydrated, with dry, tongue and mucous membranes and diminished skin turgor. His body mass index was $26.7 \mathrm{~kg} / \mathrm{m}^{2}$; there was no acanthosis nigricans and no stigmata of chronic liver disease. Temperature was $36.5^{\circ} \mathrm{C}$, heart rate was 120 beats/ min regular and blood pressure was $165 / 85$ $\mathrm{mmHg}$ (supine). The lungs were clear to auscultation, his abdomen was soft and nontender, and there were no abnormal signs in the nervous system.

Plasma biochemistry showed: sodium 152 $\mathrm{mmol} / \mathrm{l}$, potassium $4.1 \mathrm{mmol} / \mathrm{l}$, urea 13.2 $\mathrm{mmol} / \mathrm{l}$, creatinine $201 \mathrm{mmol} / \mathrm{l}$, calcium 2.36 $\mathrm{mmol} / \mathrm{l}$, glucose $86.1 \mathrm{mmol} / \mathrm{l}$, osmolality (calculated) $411 \mathrm{mOsm} / \mathrm{kg}$, alanine aminotransferase $38 \mathrm{IU} / \mathrm{I}$ (normal range <40), gamma glutamyl transferase $45 \mathrm{IU} / 1$ (normal range $<60$ ), amylase $65 \mathrm{IU} / 1$ (normal range $<70$ ), lithium $0.46 \mathrm{mmol} / 1$ (therapeutic range 0.40 0.80 ); arterial blood gas analysis: $\mathrm{pH} 7.30$, $\mathrm{pAO}_{2} 10.6 \mathrm{kPa}, \mathrm{pACO}_{2} 4.9 \mathrm{kPa}$, bicarbonate 20 $\mathrm{mmol} / \mathrm{l}$. Full blood count was normal and mean corpuscular volume was $94.7 \mathrm{fl}$. Urinalysis showed 4+ glucose, trace ketones, no protein or blood. Electrocardiogram and chest $\mathrm{X}$-ray showed no abnormalities. Urinary catheterisation revealed a residual volume of 1400 $\mathrm{ml}$ urine and central venous pressure was -9 $\mathrm{mmH}_{2} \mathrm{O}$.

Treatment was commenced with intravenous $0.9 \%$ saline, insulin, heparin and augmentin; subsequent blood cultures and midstream urine culture yielded no growth. As blood glucose fell, plasma sodium rose to 165 $\mathrm{mmol} / 1$, and, despite switching intravenous fluid replacement to $0.45 \%$ saline, subsequently rose to $174 \mathrm{mmol} / \mathrm{l}$. The patient underwent haemofiltration, which lowered plasma sodium over the next 36 hours to 151 $\mathrm{mmol} / \mathrm{l}$. Four days after admission he became febrile, temperature $37.8^{\circ} \mathrm{C}$ and complained of central abdominal pain associated with guarding and reduced bowel sounds. Serum amylase was now elevated at $495 \mathrm{IU} / 1$, abdominal ultrasound showed free fluid in the peritoneal cavity, and abdominal computed tomography scan showed an enlarged oedematous pancreas. Neither imaging technique revealed evidence of gallstones or biliary sludge; the aetiology of the pancreatitis remained unproven. The acute pancreatitis was treated with nasogastric suction and intravenous $0.45 \%$ saline and eight days after admission his plasma sodium had fallen to $141 \mathrm{mmol} / \mathrm{l}$, and blood urea to 5.7 $\mathrm{mmol} / \mathrm{l}$. Intravenous fluids and insulin were discontinued and he was transferred to oral 
food intake and a subcutaneous basal/bolus insulin regime. Despite blood glucose concentrations of 5-10 mmol/1 and absence of glycosuria, he remained polydipsic and polyuric, passing 4-6 litres of dilute urine daily (urine osmolality 192-308 mOsm/kg). Nephrogenic diabetes insipidus secondary to lithium therapy was suspected and adequate oral fluid replacement was encouraged. Lithium therapy was discontinued. $\mathrm{He}$ was discharged on gliclazide $80 \mathrm{mg}$ twice daily and four weeks later he was achieving good glycaemic control with an $\mathrm{HbAlc}$ of $3.7 \%$ (laboratory range 3-5.2\%) and intermittent hypoglycaemia, necessitating a halving of the dose of gliclazide; serum cholesterol was $5.8 \mathrm{mmol} / \mathrm{l}$ and triglycerides $3.84 \mathrm{mmol} / \mathrm{l}$.

Because of continued polyuria he was re-admitted to hospital for further investigation. His $24-\mathrm{h}$ urine volume was $4400 \mathrm{ml}$. An eight-hour water deprivation test showed a rise in plasma osmolality from 286 to $295 \mathrm{mOsm} /$ $\mathrm{kg}$; blood glucose remained between 4.2-5.2 $\mathrm{mmol} / \mathrm{l}$ throughout. Thirst, measured on a well-validated, $10-\mathrm{cm}$ long, visual analogue scale, rose normally, from 1.2 to $6.8 \mathrm{~cm}$, and drinking responses after water deprivation were normal. Despite an appropriate rise in plasma vasopressin from 1.4 to $2.8 \mathrm{pmol} / 1$, maximum urine osmolality achieved during water deprivation was subnormal at $305 \mathrm{mOsm} / \mathrm{kg}$; there was no further rise in urine osmolality after intramuscular injection of $2 \mu \mathrm{g}$ of desmopressin, with a maximum urine osmolality of $230 \mathrm{mOsm} / \mathrm{kg}$. The diagnosis of nephrogenic diabetes insipidus secondary to lithium therapy was made. Three months after admission he remained mildly polyuric, with daily urine volumes of 2.6-3.4 litres; 12 months after discharge, 24-h urine volume had fallen to 1.7 litres and early morning urine osmolality after overnight water deprivation was $824 \mathrm{mOsm} /$ $\mathrm{kg}$, indicating reversal of the nephrogenic diabetes insipidus. There has been no return of his psychiatric symptoms since cessation of lithium therapy.

\section{Discussion}

Nephrogenic diabetes insipidus is a common complication of lithium therapy, with mild polyuria occurring in up to $40 \%$ of people taking the drug, and frank diabetes insipidus occurring in $12 \% .^{3}$ Given the absence of a family history of nephrogenic diabetes insipidus, the normal plasma potassium, serum calcium and renal function, and the return of renal concentrating ability to normal after discontinuation of lithium, we have no doubts that the nephrogenic diabetes insipidus in this man was secondary to his lithium therapy. The long history of mild polyuria which preceded admission in this patient is likely to have been due to diabetes insipidus rather than mellitus, as urinalysis during this time did not reveal glycosuria.

Most patients who develop HONK are elderly, ${ }^{12}$ and have well identified precipitating causes, such as infection or drugs such as thiazide diuretics. We have recently shown that

\section{Summary points}

- hyperosmolar nonketotic coma has a $60 \%$ mortality

- $12 \%$ of patients on lithium therapy develop nephrogenic diabetes insipidus

- if diabetes develops against a background of polyuric dehydration, there is a risk of developing hyperosmolar nonketotic coma

survivors of HONK have impairment of osmotically stimulated thirst, such that they drink less when dehydrated than age-matched controls. ${ }^{4}$ This patient was relatively young to develop HONK, and had normal thirst responses during water deprivation, suggesting that the pathophysiology of the development of hypernatraemic dehydration was different from that of most patients with HONK. We hypothesize that the pre-existing nephrogenic diabetes insipidus contributed to the rapid loss of urinary free water once diabetes mellitus developed, with the consequent development of the severe hypernatraemic dehydration characteristic of hyperosmolar coma. There has only been one previous report in which lithium-induced diabetes insipidus was thought to precipitate hyperosmolar coma, ${ }^{5}$ but in that case the diagnosis of diabetes insipidus was inferred from the combination of hypernatraemia and hypotonic polyuria, despite good glycaemic control, in the immediate recovery period from HONK; no confirmatory tests of osmoregulatory function were performed. We have previously shown, however, that poorly controlled diabetes is associated with renal resistance to antidiuretic hormone, ${ }^{6}$ which may take several days of good glycaemic control to reverse, ${ }^{7}$ and in clinical practice, many patients recovering from HONK or severe ketoacidosis do have several days of hypotonic polyuria after return to euglycaemia. The explanation is that any cause of prolonged severe polyuria has a 'washout' effect on the renal medullary interstitial solute which is necessary for water reabsorption and urinary concentration, causing a transient form of nephrogenic diabetes insipidus ${ }^{7}$; we therefore believe that our paper describes the first fully documented case of HONK secondary to lithiuminduced nephrogenic diabetes insipidus.

It is rare for diabetes mellitus and diabetes insipidus to co-exist in the same patient, though cranial diabetes insipidus develops eventually in all patients with the DIDMOAD syndrome. ${ }^{8}$ The combination of central diabetes mellitus and insipidus developing after elective surgery carries an exceptionally poor prognosis, with a high mortality, ${ }^{9}$ so it is important to recognise when the two conditions occur in the same patient. We recommend that lithium therapy is carefully monitored in patients with diabetes mellitus and that patients on lithium who develop new onset diabetes mellitus should have particular 
atten-tion paid to plasma sodium concentrations and urine output.

1 Khardori R, Soler NG: Hyperosmolar hyperglycaemic nonketotic syndrome. Am Med 1984;77:899-904.

2 Marshall SM, Walker M, Alberti KGMM. Diabetic ketoacidosis and hyperglycaemic non-ketotic coma. In: Albert KGMM, De Fronzo RA, Keen H, Zimmet P, eds, International textbook of diabetes mellitus, $\mathrm{P}$, eds, Chichester: J Wiley \& Sons, 1992, pp 1151-64.

3 Martin A. Clinical management of lithium-induced polyuria. Hosp Commun Psychiatry 1993;44:427-8

4 Tia. Hosp Commun Psychiatry 1993;44:427-8. Abnormal osmoregulation in survivors of hyperosmolar Abnormal osmoregulation in survivors

5 McGregor DA, Baker AM, Appel RG, Ober KP, Zaloga GP. Hyperosmolar coma due to lithium-induced diabetes insipidus. Lancet 1995;346:413-7.
We wish to thank Professor P Baylis for measurement of plasma vasopressin and Miss Adele Makarewicz for typing the manuscript.

\title{
Coexistence of hereditary angioedema and Turner's syndrome
}

\author{
Alan Fletcher, AP Weetman
}

\begin{abstract}
Summary
A 34-year-old woman presented to the out-patient clinic with angioedema and type II hereditary angioedema was confirmed immunologically. She also volunteered she had never had a menstrual period and physical examination identified several features of Turner's syndrome. A mosaic karyotype with XY and $X O$ was found on chromosomal analysis and gonadectomy was performed in view of the high risk of gonadoblastoma. After commencing oestrogen at physiological replacement doses, the patient experienced a marked deterioration in both the severity and frequency of angioedema attacks. Coexistence of hereditary angioedema and Turner's syndrome has not previously been reported and this case highlights the detrimental $\mathrm{C1}$ inhibitor level lowering effect of oestrogen in hereditary angioedema.
\end{abstract}

Keywords: hereditary angioedema; Turner's syndrome; oestrogen therapy

A 34-year-old woman presented with several attacks of an acutely swollen tongue and abdominal pains. She was treated initially with chlorpheniramine and prednisolone and made a good recovery. The diagnosis of hereditary angioedema type II was made on finding reduced plasma $\mathrm{C} 4$, normal $\mathrm{C} 1$ inhibitor and absent $\mathrm{Cl}$ inhibitor function: $\mathrm{C} 30.93 \mathrm{~g} / 1$ (normal range 0.75-1.65), C4 $0.04 \mathrm{~g} / \mathrm{l},(0.20$ $0.65), \mathrm{C} 1$ inhibitor $0.33 \mathrm{~g} / 1$ (0.15-0.35); C1 inhibitor function was unmeasurable (normal range $40-150$ units $/ \mathrm{ml}$ ). There was no family history of hereditary angioedema. Furthermore, at her initial presentation, she stated that she had never had a menstrual period and on examination had features of Turner's syndrome
6 Thompson CJ, Frier BM. Reversal of renal resistance to vasopressin after improvement in glycaemic control in Type 1 diabetes (abstract). Diabet Med 1994;11(suppl 1):527.

7 Thompson CJ. Polyuric states in man. Clin Endocrinol Metab 1989;3:473-97.

8 Thompson CJ, Charlton J, Walford S, et al. Vasopressin secretion in the DIDMOAD (Wolfram) syndrome. Qf Med 1989;264:333-45.

9 Fraser CL, Arieff AI. Fatal central diabetes mellitus and insipidus resulting from untreated hyponatraemia: a new syndrome. Ann Intern Med 1990;112:113-9.
University of Sheffield,

Medicine, Clinica

Sciences Centre,

Hospital, Herries

Road, Sheffield S5

7AU, UK

A Fletcher

AP Weetman

Accepted 28 May 1997 with short stature, wide carrying angle and a webbed neck (cardiovascular examination was normal). Subsequent chromosomal analysis showed a mosaic karyotype consisting of one cell line with monosomy $\mathrm{X}$ and a second cell line with a $46 \mathrm{XY}$ component. Serum oestradiol was undetectable and gonadotropin levels were raised (follicle-stimulating hormone $\mathbf{5 3 . 8}$ IU/I (<21), luteinising hormone $21.8 \mathrm{IU} / 1$ $(<57))$.

The patient was given tranexamic acid as prophylaxis for attacks which occurred with a maximum frequency of one every six weeks, but she obtained little benefit. Gonadectomy was advised because of the risk of developing gonadoblastoma ${ }^{1}$ and hormone replacement therapy was withheld until the operation had been performed. Two streak ovaries were removed laparoscopically and there was no histological evidence of malignancy.

Postoperatively, hormone replacement therapy was commenced with combined conjugated oestrogen $(625 \mu \mathrm{g})$ and progesterone but within six weeks, the patient experienced a three- to four-fold increase in the frequency of her attacks of angioedema to one attack every 10-14 days. The attacks were more severe and lasted on average two hours longer. Treatment with danazol (following discontinuation of tranexamic acid) was introduced at a dose of $200 \mathrm{mg}$ daily and complete remission was induced (currently for six months). There have been no abnormalities in liver function tests.

\section{Discussion}

Hereditary angioedema is an autosomal dominant disease due to mutations within the $\mathrm{Cl}$ inhibitor gene. This leads to plasma deficiency of $\mathrm{C} 1$ inhibitor and allows the auto-activation of $\mathrm{C} 1$ and consumption of $\mathrm{C} 2$ and C4. There are two phenotypic variants: type $I$ is characterised 